\title{
Arthrogrypotic Syndrome is the Usual Misnomer in Children with Du Pan Syndrome
}

\author{
Ali Al Kaissi MD, MSc ${ }^{1,2^{*}}$, Vladimir Kenis MD³, Sami Bouchoucha MD ${ }^{4}$, Mohammad Shboul PhD \\ Franz Grill MD², Hamza Al Kaissi ${ }^{6}$, Rudolf Ganger PhD ${ }^{2}$, Susanne Gerit Kircher MD, MSc ${ }^{7}$ \\ ${ }^{1}$ Ludwig Boltzmann Institute of Osteology at the Hanusch Hospital of WGKK and AUVA Trauma Centre Meidling, \\ First Medical Department, Hanusch Hospital, Vienna, Austria \\ ${ }^{2}$ Orthopaedic Hospital of Speising, Paediatric Department, Speisinger Str. 109, Vienna-1130, Austria \\ ${ }^{3}$ Pediatric Orthopedic Institute N.A. H. Turner, Department of Foot and Ankle Surgery, Neuroorthopaedics and \\ Systemic Disorders, Parkovaya Str., 64-68, Pushkin, Saint-Petersburg, Russia \\ ${ }^{4}$ Department of Pediatric Orthopedic Surgery, Children Hospital, Tunis, Tunisia \\ ${ }^{5}$ Department of Medical Laboratory Sciences, Jordan University of Science and Technology, Irbid 22110, Jordan \\ ${ }^{6}$ Erasmus Medical University of Rome- Tor Vergata Medicine and Surgery-Italy \\ ${ }^{7}$ Institute of Medical Chemistry, Medical University of Vienna, Austria \\ "Corresponding Author \\ Dr. Ali Al Kaissi \\ Ludwig Boltzmann Institute of Osteology at the Hanusch Hospital of WGKK and AUVA Trauma Centre Meidling \\ First Medical Department, Hanusch Hospital. Heinrich Collin Str. 30 A-1140. 2Orthopaedic Hospital of Speising \\ Speisinger strasse 109 A-1130, Vienna \\ Austria. \\ Tel: $+43180182-1260$ \\ Fax: $+43180182-1494$ \\ Email: ali.alkaissi@oss.at
}

Received:13 November 2019; | Revised:11 December 2019; | Accepted:03 June 2020

\section{Abstract}

Objective: The term arthrogrypotic syndrome is of common usage by different medical disciplines. The hallmarks of acromesomelic dysplasia Du Pan Syndrome are characteristic facial features, severe growth deficiency and multiple contractures.

Material and Methods: Seven children (four females and three males) age range of (1-10 years) were sought in our departments from the period of 1994-2018. All patients were given the diagnosis of arthrogryposis in other institutions. Though, all demonstrated the classical features of abnormalities which are consistent with the diagnosis of Du Pan syndrome.

Results: The distinctive clinical and radiological phenotype was consistent with Du Pan syndrome. Strikingly, multiple dislocations along the hips and knees, elbows and ankle joints were detected which gives the false impression of arthrogrypotic syndrome.

Conclusion: Unfortunately, on the one hand, the terms arthrogrypotic and or amyoplasia syndrome still prevails in many medical disciplines. The clinical phenotype is the corner stone in establishing diagnoses in the vast majority of children who are born with multiple contractures. On the other hand, it is mandatory to search for extra-skeletal malformations in patients with Du Pan syndrome. 


\section{Introduction}

Children born with multiple contractures are usually given the term of arthrogryposis by overlooking the associated clinical features. The term arthrogryposis does not represent a specific diagnosis, in most cases arthrogryposis is a symptom complex. There is some confusion in the terminology of Du Pan Syndrome (MIM 228900), as it has been reported more than once under different titles. In addition it was reported by Grebe et al in 1955 as Grebe's 'other' syndrome (GrebeQuelce-Selgado syndrome; MIM 200700).1 The hallmarks of the condition are fibular aplasia, a complex form of brachydactyly and very hypoplastic ('ball-like') toes. The length of individual fingers can be very variable. ${ }^{[1,2]}$

In the initial report by Martin Du Pan et al the cardinal features were brachydactyly and bilateral absence of the fibulae. ${ }^{[3]}$ In the hands, the thumbs were radially deviated and the index finger was abnormal, due to an absent proximal phalanx. The middle and ring fingers were deviated in an ulnar direction and the middle phalanges of the index, middle and little fingers were short. The carpal bones were hypoplastic. The feet were in an equinovalgus position and the phalanges of all the toes were hypoplastic or absent.

Grebe et al reported two sibs who were the offspring of first cousin parents. ${ }^{[1]}$ The sibs had short metacarpals, small carpals, a trapezoid configuration to the middle phalanx of the index finger, and radial deviation of that finger. The fibulae were bilaterally almost absent, with tibiotarsal dislocation, and the toes were short and deviated laterally.

Mutations in the cartilage-derived morphogenic protein-1 (CDMP1) also known as growth and differentiation factor 5 (GDF5) gene account for several related types of skeletal dysplasia, a rare subgroup of osteochondrodysplasias. The phenotype of these skeletal malformations ranging from prenatally lethal to very mild chondrodysplasias. Dominant mutations in GDF5 were previously reported in angel-shaped phalango-epihyseal dysplasia (ASPED; MIM 105835), ${ }^{[4,5]}$ brachydactyly type A2
(BDA2, MIM 112600), ${ }^{[6-8]}$ proximal symphalangism 1B (SYM1B, MIM 615298) [7,9], multiple synostoses syndrome type 2 (SYNS2, MIM 610017) ${ }^{[10,11]}$ brachydactyly C (BDC; MIM $113100),{ }^{[4,12]}$ whereas severe sever entities of grebetype chondrodysplasia (GTC, MIM 200700), ${ }^{[13-16]}$ Hunter-Thompson (AMDH, MIM 201250), ${ }^{[9,17]}$ Brachydactyly, type A1, C (BDA1C, MIM 615072) ${ }^{[18]}$ and fibular hypoplasia and complex brachydactyly (Du Pan syndrome) ${ }^{[19,20]}$ were caused by homozygous loss-of-function mutations. A dominant transmission was also reported $\mathrm{Du}$ Pan syndrome and BDA1C. ${ }^{[18,21]}$ Moreover, a single nucleotide polymorphism (SNP) in the 5'UTR of GDF5 gene was reported to cause osteoarthritis (OS5, MIM 612400) in Asian populations. ${ }^{[22]}$

The GDF5 gene is localized on chromosome $20 \mathrm{q}^{[11,22]}$ and comprises only two coding exons. GDF5 (also known as bone morphogenetic proteins 14 (BMP14)) belongs to a transforming growth factor beta (TGF-b) superfamily was found to be expressed in cartilaginous tissues of the long bones during embryonic development and binds with BMP receptors BMPR1A and BMPR1B, with high affinity to BMPR1B during development. ${ }^{[23-26]}$ GDFs like other BMPs have a crucial role in cartilage formation and chondrocyte differentiation. ${ }^{[24,25,27-30]} \mathrm{Du}$ Pan syndrome. is very rare autosomal recessive condition caused by homozygous or compound heterozygous mutations in the GDF5 gene, usually disrupt GDF-5 receptor binding and/or activity, 19 More than 40 mutations in GDF5 gene have been reported so far, with only 3 mutations have been found to associated with $\mathrm{Du}$ Pan syndrome. ${ }^{[19,20,31]}$ Stange et al Has identified a homozygous hypomorphic mutation in BMPR1B that cause $\mathrm{Du}$ Pan acromesomelic dysplasia in Moroccan family. ${ }^{[32]}$

\section{Material and Patients}

The study protocol was approved by the Ethics Committee of the Turner Scientific Research Institute, No.3/2016, Saint-Petersburg, Russia. A signed consent form was obtained from the patient's Guardians. This study was conducted based on clinical and radiographic evaluation of a group of 
children and their parents/grandparents and relatives and was carried out between first of January 1994 to March 2018. All patients showed the classical clinical phenotype of Du Pan syndrome showed severe short stature (ranging between -3/-4 SD), short limbs and acromelia of the upper limbs. The clinical phenotype of all children showed frontal bossing, rounded facies, mid-facial hypoplasia, up slanting palpebral fissure, short philtrum, low set ears (but not markedly malformed) and micrognathia. Musculo-skeletal examination, all children manifested stiff/rigid joints. Intelligence, communicative skills, hearing, vision and neurological examination were normal.

All children manifested the complex type of brachydactyly (button-like and radially deviated thumbs, short metacarpals, short phalanges and hypoplasia of the carpal bones. Equinovarus deformity of the feet, ball like hypoplastic toes and hypoplastic nails. At birth all these children have been given the diagnosis of arthrogryposis multiplex.
Hip contractures in conjunction with bilateral hip dislocation (manifested by flexion, abduction, and external rotation). Knee deformities were another prominent feature in all patients. Fixed flexion deformity of the knees (it was the most disabling deformity affecting the locomotor system). The foot and ankle deformities showed tibio-tarsal dislocation, and the toes were short and deviated laterally. Developmental skills were severely disturbed, particularly of gross motor development, which was markedly retarded because of multiple dislocations and congenital fixed flexion deformity of the knees and gross developmental retardation of the fine motor because of the button like fingers. The latter is a distinctive abnormality in children with Du Pan syndrome.

The hallmarks of Du pan syndrome are severe short stature (-4SD), acromelia of the upper and lower limbs, fibular aplasia, a complex form of brachydactyly and very hypoplastic ('ball-like') toes and club foot (fig 1a-d).

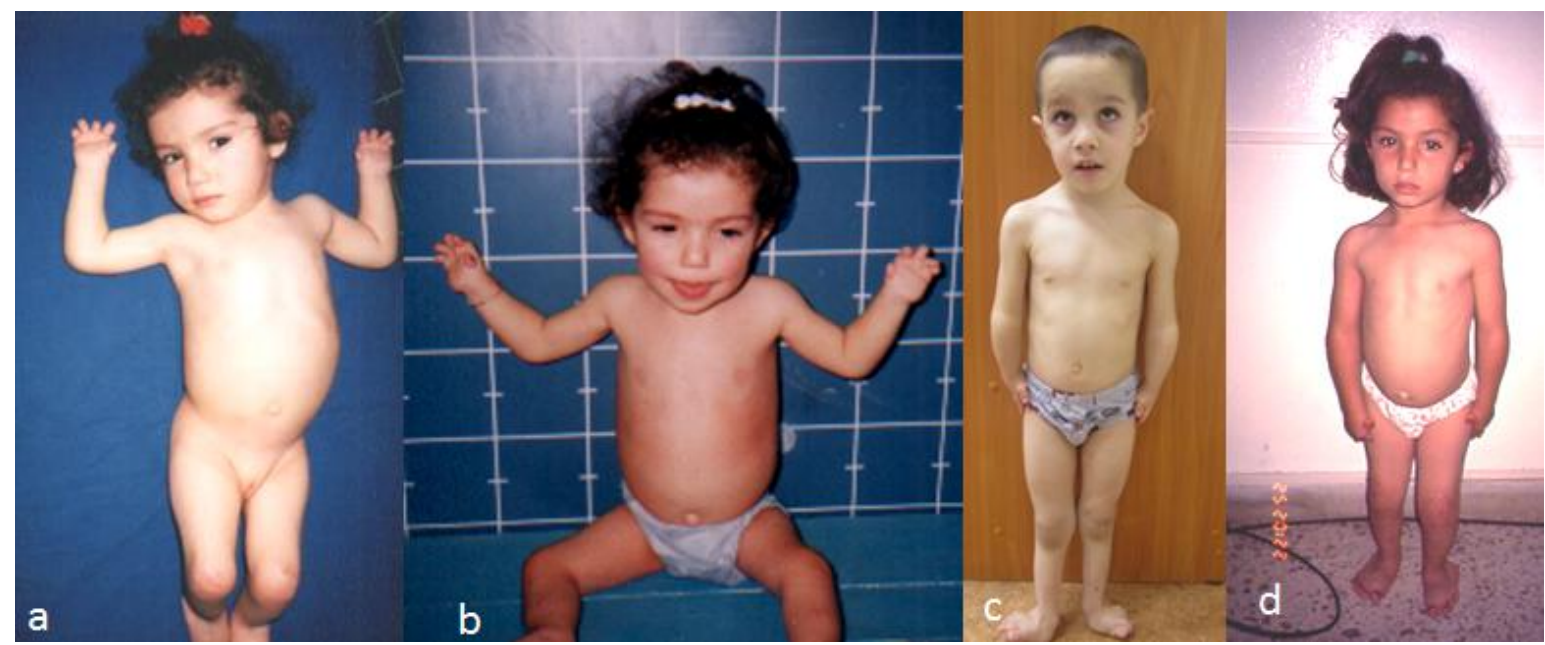

Figure 1 (a,b,c,d): The clinical phenotype in children with Du Pan syndrome (age from 18 months-7 years). The hallmarks of Du pan syndrome are severe short stature (-4SD), acromelia of the upper and lower limbs, fibular aplasia, a complex form of brachydactyly and very hypoplastic ('ball-like') toes and club foot

\section{Results}

All children manifested limb shortening which became progressively more severe distally. Dysplastic dislocated hips, short tibiae, fibulae replaced by distal triangular remnants and single phalanges in the toes (Bilateral and symmetrical dysplasia of the capital femoral epiphyses with subsequent development of bilateral hip dislocation in 9 out of ten patients). Upper limbs, all manifested dislocated hypoplastic radial head \&ulna, with severe bone retardation, and massive aplasia of the metacarpal-phalangeal, and only a small trace of bone in the fingers left.

AP hand radiograph in a one-year-old boy showed ulnar deviation of the hand, short phalanges, short hypoplastic metacarpals, hypoplastic thumbs, radially deviated thumbs and the index finger plus 
abnormalities of the index fingers. The middle and ring fingers are deviated in an ulnar direction and the middle phalanges of the index, middle and little fingers were short. The carpal bones are hypoplastic, note the button like digits (fig 2a). AP elbow radiograph showed radio-ulnar dislocation in a-3 year-old-girl because radial head dysplasia (2b). AP standing radiograph in a 7-year-old-girl showed coxa valga, defective ossification of os pubis, middiaphyseal dysplasia, bilateral aplastic fibulae (fig 2c). 3D reconstruction CT scan of the foot of an 8year-old boy with Du Pan syndrome showed hypoplastic metatarsals associated with severe hypoplasia of the toes including phalanges and very hypoplastic ('ball-like') toes (2d). AP standing radiograph of a-4-year-old girl showed bilateral hip dislocation (severe dysplasia of; acetabulae, capital femoral epiphyses, and defective ossification of os pubis), bilateral knee dislocation associated with absent patellae (fig 2e). AP standing radiograph of the legs in a 10-year-old-boy showed bilateral aplastic fibulae and bilateral tibio-tarsal dislocation (fig 2f).

Laboratory investigations included karyotype blood electrolytes, liver functions, kidney functions, showed normal results. All showed normal calcium and normal phosphate levels normal, ranging between (0.83-1.48 mmol/l). Serum 25-hydroxy vitamin $\mathrm{D}$ was evaluated by radioimmunoassay and was found at the level average of about (39-42 nanograms per milliliter). MPS (mucopolysaccharidosis) urine screening and plasma chromatographic examinations yielded normal results. Ultrasound (abdominal and pelvic) examination revealed nothing of significance. Echocardio-doppler: normal.

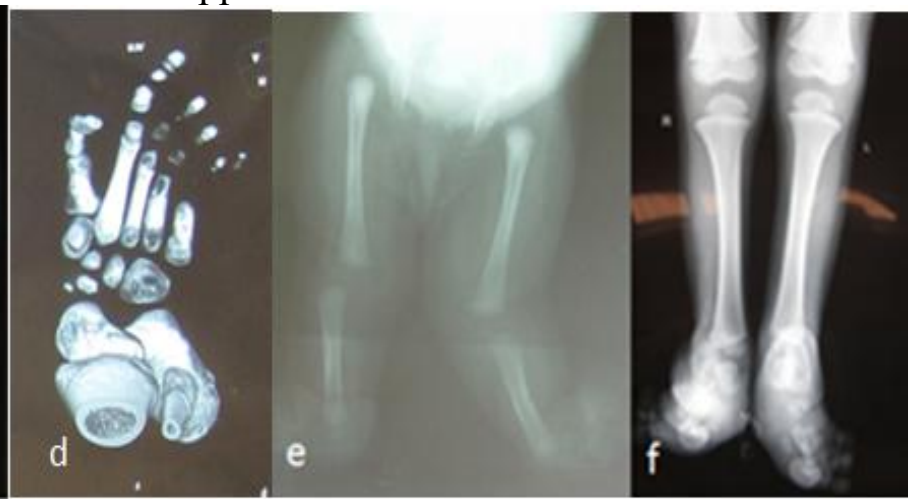

Figure 2 (a-f): AP hand radiograph in a one-year-old boy showed ulnar deviation of the hand, short phalanges, short hypoplastic metacarpals, hypoplastic thumbs, radially deviated thumbs and the index finger plus abnormalities of the index fingers. The middle and ring fingers are deviated in an ulnar direction and the middle phalanges of the index, middle and little fingers were short. The carpal bones are hypoplastic, note the button like digits (fig 2a). AP elbow radiograph showed radio-ulnar dislocation in a-3 year-old-girl because radial head dysplasia (2b). AP standing radiograph in a 7-year-old-girl showed coxa valga, defective ossification of os pubis, mid-diaphyseal dysplasia, bilateral aplastic fibulae (fig 2c). 3D reconstruction CT scan of the foot of an 8-year-old boy with Du Pan syndrome showed hypoplastic metatarsals associated with severe hypoplasia of the toes including phalanges and very hypoplastic ('ball-like') toes (2d). AP standing radiograph of a-4-year-old girl showed bilateral hip dislocation (severe dysplasia of; acetabulae, capital femoral epiphyses, and defective ossification of os pubis), bilateral knee dislocation associated with absent patellae (fig 2e). AP standing radiograph of the legs in a 10-year-old-boy showed bilateral aplastic fibulae and bilateral tibio-tarsal dislocation (fig 2f).

\section{Discussion}

An arthrogrypotic condition is generally classified by group. ${ }^{[33,34]}$ Group I describe children born with involvement of the limbs only (distal arthrogryposis such as Freeman-Sheldon syndrome) and Beals syndrome. Group II describes children born with involvement of the limbs and other body areas (abnormal craniofacial contour, spine, and or additional congenital anomalies e.g cardiac/ and or genito-urinary defects). Escobar syndrome and Larsen syndrome have been wrongly included in this group. 
Group III describes children born with involvement of the limbs and the central nervous system as, seen in children with sacral agenesis.

Al Kaissi et al described two different families, in which both manifested the associations between maternal hyperthermia in connection with hypohidrotic ectodermal dysplasia and the birth of children with EEC syndrome and or phacomelia. ${ }^{[35]}$

$\mathrm{Du}$ Pan syndrome is characterized by severe hypoplastic/dysplastic short tubular and round, hand and feet bones, absent or rudimentary fibulae, hypoplastic distal ulnae, grossly normal humeri, femora and tibiae, and valgus deformity of the feet. Carpal/tarsal fusions are distinctive features. 1,3

The similar Hunter. Thompson syndrome shows more severe joint abnormalities (dislocated hips, knees, radial heads and hypoplastic femoral condyles and short forearm and leg bones. There are slightly different radiological aspects of the hands and feet. However radial head and knee dislocations occur in Du Pan syndrome and minor round bone fusions were observed in HunterThompson syndrome. ${ }^{[21,36]}$

Multiple Joint dislocation is a common clinical phenotype usually seen in children with Larsen syndrome, ${ }^{[37]}$ Desbuquois syndrome, ${ }^{[38]}$ multiple joint dislocation with joint laxity (Beighton type),[39] and otopalatodigital syndrome. ${ }^{[40]}$

Reduction of dislocated syndromic hips has led to high rates of recurrent dislocation, stiffness, osteonecrosis, and persistent deformity. A longterm follow-up study found that dislocated arthrogrypotic hips were generally painless and stable after open reduction with any necessary pelvic or femoral osteotomis. ${ }^{[41]}$

Congenital hyperextension deformities of the knee comprise a spectrum of lesions, including simple hyperextension, subluxation, and complete dislocation. At least half of the babies presenting with these deformities will have some passive flexion at birth that can be managed with casting and/or a Pavlik harness to maintain knee flexion for a few weeks. Fixed subluxation/dislocation is more difficult to treat and often accompanies the fixed dislocation of the hips in the neonate. ${ }^{[22-44]}$

Traditional treatment for congenital knee dislocation involves the extensive lengthening of the quadriceps mechanism to achieve flexion and an anterior arthrotomy to release the intra- and extra- articular adhesions that prevent congruous knee flexion and to mobilize the patellofemoral joint. ${ }^{[45]}$

The literature suggests that patients with nonsyndromic knee dislocations respond well to conservative management of these dislocations with serial casting and or traction and may have a better prognosis than patients with syndromic multiple dislocations. Flexion contractures of the knees may be the most disabling deformity, because the quadriceps extensor mechanism often is poorly defined or absent in a patient with a knee contracture. These contractures are difficult to treat, and multiple surgical techniques have been proposed. Recurrence is common regardless the technique. ${ }^{[46]}$ Stretching casts may be beneficial for a neonate, although care must be taken to avoid posterior dislocation. ${ }^{[47]}$

\section{In Summary}

$\mathrm{Du}$ Pan syndrome is a syndrome of malformation complex caused by dominant or recessive mutations in GDF5 or BMPR1B genes. Less than 30 cases have been described in the literature so far. This syndrome is allelic to other skeletal malformations with overlapping clinical presentations causing a diagnostic challenge, particularly with arthrogryposis multiplex congenita and or amyoplasia. The misdiagnosis of syndromic entities by the vast majority of pediatricians, physicians and orthopedic surgeons, particularly when dealing with disorders presented with multiple contractures is apparent. Multiple contractures are classified within the diagnosis of arthrogryposis multiplex. The latter is categorized within congenital myopathy. Congenital myopathy often entails a long and strenuous journey of unnecessary investigations. The distinctive clinical and radiological phenotypic characterizations are fundamental tools to specify and successfully categorize cases of multiple contractures into their respective diagnosis.

The initial clinical assessment of any child with multiple contractures should be based on family history and the clinical phenotypic characterization. Careful clinical examination of the craniofacial contour, musculoskeletal system, searching and exploring for minor and major malformations and so forth are mandatory 
parameters. Otherwise, the journey of such families within different medical departments would be more or less futile. The clinical sign is not a sign if a physician cannot read it and similarly if a radiological feature is missing, abnormalities are difficult to recognize. Alleviating pain and discomfort for families with children suffering from severe locomotor disability is the main objective for any medical discipline. To mitigate the patients' and their families' suffering, diagnosis with the outmost precision should be given.

\section{References}

1 Grebe H. Chondrodysplasie. Rome Ist Gregor Mendel 1955;:Pp. 300-303.

2 Al Kaissi A, Chehida FB, Ghachem MB, et al. Distinctive tomographic features of atlantoaxial dislocation in a boy with acromesomelic dysplasia du Pan syndrome. Clin Dysmorphol 2009;18:122-126.

3 C Martin du P. Absence congenitale du perone sans deformation $\mathrm{du}$ tibia. Curieuses deformations congenitales des mains. Rev Orthop 1924;11:227-34.

4 Gutierrez-Amavizca BE, Brambila-Tapia AJ, Juarez-Vazquez CI, Holder-Espinasse $M$, Manouvrier-Hanu S, Escande F, Barros-Nunez P. A novel mutation in CDMP1 causes brachydactyly type $\mathrm{C}$ with "angel-shaped phalanx". A genotype-phenotype correlation in the mutational spectrum. Eur J Med Genet 2012; 55(11): 611-614 DOI: 10.1016/j.ejmg.2012.07.004

5 Holder-Espinasse M, Escande F, Mayrargue E, Dieux-Coeslier A, Fron D, Doual-Bisser A, Boute-Benejean O, Robert Y, Porchet N, Manouvrier-Hanu S. Angel shaped phalangeal dysplasia, hip dysplasia, and positional teeth abnormalities are part of the brachydactyly $\mathrm{C}$ spectrum associated with CDMP-1 mutations. J Med Genet 2004; 41(6): e78 DOI: 10.1136/jmg.2003.013904

6 Khan S, Mudassir M, Khan N, Marwat A. Brachdactyly Instigated as a Result of Mutation in GDF5 and NOG Genes in Pakistani Population. Pak J Med Sci 2018; 34(1): 82-87 DOI: 10.12669/pjms.341.12885
7 Seemann P, Schwappacher R, Kjaer KW, Krakow D, Lehmann K, Dawson K, Stricker S, Pohl J, Ploger F, Staub E, Nickel J, Sebald W, Knaus P, Mundlos S. Activating and deactivating mutations in the receptor interaction site of GDF5 cause symphalangism or brachydactyly type A2. J Clin Invest 2005; 115(9): 2373-2381 DOI: $\underline{10.1172 / J C I 25118}$

8 Kjaer KW, Eiberg H, Hansen L, van der Hagen CB, Rosendahl K, Tommerup N, Mundlos S. A mutation in the receptor binding site of GDF5 causes Mohr-Wriedt brachydactyly type A2. J Med Genet 2006; 43(3): 225-231 DOI: 10.1136/jmg.2005.034058

9 Yang W, Cao L, Liu W, Jiang L, Sun M, Zhang D, Wang S, Lo WHY, Luo Y, Zhang X. Novel point mutations in GDF5 associated with two distinct limb malformations in Chinese: brachydactyly type $\mathrm{C}$ and proximal symphalangism. J Hum Genet 2008; 53(4): 368-374 DOI: $10.1007 / \mathrm{s} 10038-008-0253-7$

10 Dawson K, Seeman P, Sebald E, King L, Edwards M, Williams J, 3rd, Mundlos S, Krakow D. GDF5 is a second locus for multiple-synostosis syndrome. Am $\mathbf{J} \mathbf{H u m}$ Genet 2006; 78(4): 708-712 DOI: $\underline{10.1086 / 503204}$

11 Degenkolbe E, Konig J, Zimmer J, Walther M, Reissner C, Nickel J, Ploger F, Raspopovic J, Sharpe J, Dathe K, Hecht JT, Mundlos S, Doelken SC, Seemann P. A GDF5 point mutation strikes twice--causing BDA1 and SYNS2. PLoS Genet 2013; 9(10): e1003846 DOI: $10.1371 /$ journal.pgen. 1003846

12 Uyguner ZO, Kocaoglu M, Toksoy G, Basaran $\mathrm{S}$, Kayserili $\mathrm{H}$. Novel indel Mutation in the GDF5 Gene Is Associated with Brachydactyly Type C in a Four-Generation Turkish Family. Mol Syndromol 2014; 5(2): 81-86 DOI: $\underline{10.1159 / 000357264}$

13 Thomas JT, Kilpatrick MW, Lin K, Erlacher L, Lembessis P, Costa T, Tsipouras P, Luyten FP. Disruption of human limb morphogenesis by a dominant negative mutation in CDMP1. Nat Genet 1997; 17(1): 58-64 DOI: 10.1038/ng0997-58

14 Al-Yahyaee SA, Al-Kindi MN, Habbal O, Kumar DS. Clinical and molecular analysis of Grebe acromesomelic dysplasia in an Omani 
family. Am J Med Genet $\boldsymbol{A}$ 2003; 121A(1): 914 DOI: $\underline{10.1002 / \text { ajmg.a.20256 }}$

15 Stelzer C, Winterpacht A, Spranger J, et al. Grebe dysplasia and the spectrum of CDMP1 mutations. Pediatr Pathol Mol Med 2003;22:77-85. doi:10.1080/15227950307698

16 Mumtaz S, Riaz HF, Touseef M, Basit S, Faiyaz Ul Haque M, Malik S. Recurrent mutation in CDMP1 in a family with Grebe chondrodysplasia: broadening the phenotypic manifestation of syndrome in Pakistani population. Pak J Med Sci 2015; 31(6): 15421544 DOI: $10.12669 /$ pjms.316.8115

17 Thomas JT, Lin K, Nandedkar M, Camargo M, Cervenka J, Luyten FP. A human chondrodysplasia due to a mutation in a TGFbeta superfamily member. Nat Genet 1996; 12(3): 315-317 DOI: 10.1038/ng0396-315

18 Byrnes AM, Racacho L, Nikkel SM, Xiao F, MacDonald H, Underhill TM, Bulman DE. Mutations in GDF5 presenting as semidominant brachydactyly A1. Hum Mutat 2010; 31(10): 1155-1162 DOI: 10.1002/humu.21338

19 Faiyaz-Ul-Haque M, Ahmad W, Zaidi SH, Haque S, Teebi AS, Ahmad M, Cohn DH, Tsui LC. Mutation in the cartilage-derived morphogenetic protein-1 (CDMP1) gene in a kindred affected with fibular hypoplasia and complex brachydactyly (DuPan syndrome). Clin Genet 2002; 61(6): 454-458 DOI: 10.1034/j.1399-0004.2002.610610.x

20 Douzgou S, Lehmann K, Mingarelli R, Mundlos S, Dallapiccola B. Compound heterozygosity for GDF5 in Du Pan type chondrodysplasia. Am J Med Genet A 2008; 146A(16): 2116-2121 DOI: 10.1002/ajmg.a.32435

21 Szczaluba K, Hilbert K, Obersztyn E, Zabel B, Mazurczak T, Kozlowski K. Du Pan syndrome phenotype caused by heterozygous pathogenic mutations in CDMP1 gene. Am J Med Genet $\boldsymbol{A}$ 2005; 138(4): 379-383 DOI: 10.1002/ajmg.a.30969

22 Miyamoto Y, Mabuchi A, Shi D, Kubo T, Takatori Y, Saito S, Fujioka M, Sudo A, Uchida A, Yamamoto S, Ozaki K, Takigawa M, Tanaka T, Nakamura Y, Jiang Q, Ikegawa S. A functional polymorphism in the 5' UTR of
GDF5 is associated with susceptibility to osteoarthritis. Nat Genet 2007; 39(4): 529-533 DOI: $\underline{10.1038 / 2005}$

23 Chang SC, Hoang B, Thomas JT, et al. Cartilage-derived morphogenetic proteins. New members of the transforming growth factor- $\beta$ superfamily predominantly expressed in long bones during human embryonic development. J Biol Chem 1994;269:28227-34.

24 Settle SH,Rountree RB, Sinha A, et al. Multiple joint and skeletal patterning defects caused by single and double mutations in the mouse Gdf6 and Gdf5 genes. Dev Biol 2003;254:116-30. doi:10.1016/S0012-1606(02)00022-2

25 Storm EE,Kingsley DM.Joint patterning defects caused by single and double mutations in members of the bone morphogenetic protein (BMP) family.Development 1996;122:3969-79.

26 Nickel J, Kotzsch A, Sebald W, Mueller TD. A single residue of GDF-5 defines binding specificity to BMP receptor IB. J Mol Biol 2005; 349(5): 933-947 DOI: 10.1016/j.jmb.2005.04.015

27 Khan S, Basit S, Khan MA, Muhammad N, Ahmad W. Genetics of human isolated acromesomelic dysplasia. Eur J Med Genet 2016; 59(4): 198-203 DOI: 10.1016/j.ejmg.2016.02.011

28 Storm EE, Kingsley DM. GDF5 coordinates bone and joint formation during digit development. Dev Biol 1999; 209(1): 11-27 DOI: $10.1006 /$ dbio.1999.9241

29 Hotten GC, Matsumoto T, Kimura M, Bechtold RF, Kron R, Ohara T, Tanaka H, Satoh Y, Okazaki M, Shirai T, Pan H, Kawai S, Pohl JS, Kudo A. Recombinant human growth/differentiation factor 5 stimulates mesenchyme aggregation and chondrogenesis responsible for the skeletal development of limbs. Growth Factors 1996; 13(1-2): 65-74 DOI: $10.3109 / 08977199609034567$

30 Klammert U, Mueller TD, Hellmann TV, Wuerzler KK, Kotzsch A, Schliermann A, Schmitz W, Kuebler AC, Sebald W, Nickel J. GDF-5 can act as a context-dependent BMP-2 antagonist. BMC Biol 2015; 13: 77 DOI: 10.1186/s12915-015-0183-8

31 Umair M, Rafique A, Ullah A, Ahmad F, Ali RH, Nasir A, Ansar M, Ahmad W. Novel 
homozygous sequence variants in the GDF5 gene underlie acromesomelic dysplasia typegrebe in consanguineous families. Congenit Anom (Kyoto) 2017; 57(2): 45-51 DOI: $\underline{10.1111 / \text { cga. } 12187}$

32 Stange K, Desir J, Kakar N, Mueller TD, Budde BS, Gordon CT, Horn D, Seemann P, Borck G. A hypomorphic BMPR1B mutation causes du Pan acromesomelic dysplasia. Orphanet J Rare Dis 2015; 10: 84 DOI: 10.1186/s13023-015-0299-5

33 Hall JG. Arthrogryposes (multiple congenital contractures). In: Emery and Rimoin's Principles and Practice of Medical Genetics. 2013. 1-101. doi:10.1016/B978-0-12-383834$\underline{6.00168-3}$

34 Hall JG. Arthrogryposis (multiple congenital contractures): diagnostic approach to etiology, classification, genetics, and general principles. Eur J Med Genet 2014; 57(8): 464-472 DOI: 10.1016/j.ejmg.2014.03.008

35 Kaissi AA, Ghachem MB, Necib MN, Chehida FB, Karoui H, Baraitser M. Hypohidrotic ectodermal dysplasia with tibial aplasia. Clin Dysmorphol 2002; 11(3): 175-178 DOI: 10.1097/00019605-200207000-00004

36 Al Kaissi A, Ghachem MB, Chehida FB, Kozlowski K. Acromesomelic dysplasia du Pan. Magyar Radiologia 2005;79:234-239.

37 Girisha KM, Bidchol AM, Graul-Neumann L, Gupta A, Hehr U, Lessel D, Nader S, Shah H, Wickert J, Kutsche K. Phenotype and genotype in patients with Larsen syndrome: clinical homogeneity and allelic heterogeneity in seven patients. BMC Med Genet 2016; 17: 27 DOI: 10.1186/s12881-016-0290-6

38 Bonafe L, Cormier-Daire V, Hall C, Lachman R, Mortier G, Mundlos S, Nishimura G, Sangiorgi L, Savarirayan R, Sillence D, Spranger J, Superti-Furga A, Warman M, Unger S. Nosology and classification of genetic skeletal disorders: 2015 revision. $\boldsymbol{A m} \boldsymbol{J}$ Med Genet A 2015; 167A(12): 2869-2892 DOI: $10.1002 /$ ajmg.a.37365
39 Al Kaissi A, Chehida FB, Ghachem MB, Klaushofer K, Grill F. A hypoplastic atlas and long odontoid process in a girl manifesting phenotypic features resembling spondyloepimetaphyseal dysplasia joint laxity syndrome. Skeletal Radiol 2008; 37(5): 469473 DOI: $10.1007 / \mathrm{s} 00256-007-0443-\mathrm{y}$

40 Kaissi AA, Kraschl R, Kaulfersch W, Grill F, Ganger R. Extended phenotypes in a boy and his mother with oto-palato-digital-syndrome type II. Clin Case Rep 2015; 3(9): 762-766 DOI: $10.1002 / \mathrm{ccr} 3.317$

41 Yau PWP, Chow W, Li YH, et al. Twenty-year follow-up of hip problems in arthrogryposis multiplex congenita. J Pediatr Orthop 2002;22:359-63. doi:10.1097/01241398200205000-00018

42 Bell MJ,Atkins RM,Sharrard WJW.Irreducible congenital dislocation of the knee: Aetiology and management.J Bone Jt Surg-Ser B 1987;69:403-6.

43 Bensahel H1,Dal Monte A,Hjelmstedt A, Bjerkreim I, Wientroub S, Matasovic T, Porat S B V. Congenital dislocation of the knee. $\boldsymbol{J}$ Pediatr Orthop 1989;2:174-7.

44 Haga N,Nakamura S,Sakaguchi R,et al. Congenital dislocation of the knee reduced spontaneously or with minimal treatment. $J$ Pediatr Orthop 1997;17:59-62. doi:10.1097/00004694-199701000-00014

45 Schindler O. Insall \& Scott Surgery of the Knee. J Bone Joint Surg Br 2006;88-B:1678-1678. doi:10.1302/0301-620x.88b9.18858

46 Thomas B, Schopler S, Wood W, et al. The knee in arthrogryposis. Clin Orthop Relat Res 1985;NO. 194:87-92.

47 Ooishi T,Sugioka Y,Matsumoto S,et al. Congenital dislocation of the knee: Its pathologic features and treatment. Clin Orthop Relat Res 1993;:187-92. 